\title{
Patient and operative factors associated with complications following adolescent idiopathic scoliosis surgery: an analysis of 36,335 patients from the Nationwide Inpatient Sample
}

\author{
Rafael De la Garza Ramos, MD, ${ }^{1}$ C. Rory Goodwin, MD, PhD, ${ }^{1}$ Nancy Abu-Bonsrah, BS, ${ }^{1}$ \\ Amit Jain, MD, ${ }^{2}$ Emily K. Miller, MD, ${ }^{2}$ Nicole Huang, BS, ${ }^{1}$ Khaled M. Kebaish, MD, ${ }^{2}$ \\ Paul D. Sponseller, MD, ${ }^{2}$ and Daniel M. Sciubba, MD' \\ Departments of ${ }^{1}$ Neurosurgery and ${ }^{2}$ Orthopaedic Surgery, Johns Hopkins University School of Medicine, Baltimore, Maryland
}

\begin{abstract}
OBJECTIVE The aim of this study was to investigate the incidence of and factors associated with complications following idiopathic scoliosis surgery in adolescents.

METHODS The Nationwide Inpatient Sample database was used to identify patients 10-18 years of age who had undergone spinal fusion for adolescent idiopathic scoliosis (AIS) from 2002 to 2011. Twenty-three unique in-hospital postoperative complications, including death, were examined. A series of logistic regressions was used to determine if any demographic, comorbid, or surgical parameter was associated with complication development. Results of multiple logistic regression analyses were reported as odds ratios with $95 \%$ confidence intervals. All analyses were performed after the application of discharge weights to produce national estimates.
\end{abstract}

RESULTS A total of 36,335 patients met the study inclusion criteria, $7.6 \%$ of whom $(95 \% \mathrm{Cl} 6.3 \%-8.9 \%)$ developed at least one in-hospital complication. The 3 most common complications were respiratory failure (3.47\%), reintubation $(1.27 \%)$, and implant related (1.14\%). Major complications such as death, pancreatitis, disseminated intravascular coagulation, visual loss, spinal cord injury, cardiac arrest, sepsis, nerve root injury, deep vein thrombosis, pulmonary embolism, shock, malignant hyperthermia, myocardial infarction, and iatrogenic stroke each had an incidence $\leq 0.2 \%$. On multiple logistic regression analysis, an increasing age (OR 0.80 ) was associated with significantly lower odds of complication development; patients who were male (OR 1.80) or who had anemia (OR 2.10), hypertension (OR 2.51), or hypothyroidism (OR 2.27) or underwent revision procedures (OR 5.55) were at a significantly increased risk for complication development. The rates of postoperative complications for posterior, anterior, and combined approaches were $6.7 \%, 10.0 \%$, and $19.8 \%$, respectively ( $p<0.001)$. Length of fusion ( $<8 \mathrm{vs} \geq 8$ levels) was not associated with complication development $(p=0.311)$.

CONCLUSIONS Analysis of 36,335 patients who had undergone surgery for AIS revealed that younger patients, male patients, patients with a history of anemia, hypertension, or hypothyroidism, as well as those undergoing revision or anterior or combined approaches may have higher rates of postoperative complications. However, the overall complication rate was low $(7.6 \%)$, and major complications had a rate $\leq 0.2 \%$ for each event. These findings suggest that surgery for AIS remains relatively safe, and future prospective investigations may further help to decrease the postoperative morbidity rate.

http://thejns.org/doi/abs/10.3171/2016.6.PEDS16200

KEY WORDS adolescent idiopathic scoliosis; complications; surgery; Nationwide Inpatient Sample; spine

A DOLESCENT idiopathic scoliosis (AIS) is the most common form of structural coronal spine deformity in the younger population, presenting between the ages of 10 years and skeletal maturity, typically 18 years old.${ }^{14}$ Corrective surgery is usually reserved for patients with curves of at least $50^{\circ}$, rapidly progressive curves in skeletally immature patients, progressive double curves, curves producing significant trunk imbalance, curves not controlled by bracing, and, on some occasions, curves causing psychological distress due to cosmetic ap-

ABBREVIATIONS AIS = adolescent idiopathic scoliosis; DISCWT = discharge weight; DVT = deep vein thrombosis; NIS = Nationwide Inpatient Sample; PE = pulmonary embolism; rhBMP-2 = recombinant human bone morphogenetic protein-2; SRS = Scoliosis Research Society.

SUBMITTED April 8, 2016. ACCEPTED June 8, 2016.

INCLUDE WHEN CITING Published online August 26, 2016; DOI: 10.3171/2016.6.PEDS16200. 
pearance. ${ }^{23}$ Although surgery provides good outcomes for most patients, ${ }^{16}$ curvature correction is not without the risk of medical or surgical complications. ${ }^{7}$

In 2006, the Scoliosis Research Society (SRS) published a report on 6334 surgical AIS patients from its morbidity and mortality database from 2001 to 2003 . $^{7}$ The authors found a complication rate of $5.7 \%$, which included pulmonary complications, implant-related complications, wound infections, and spinal cord injuries. Although various studies have reported complications after surgery for AIS, $4,7,27,28$ there is limited information on the risk of major complications such as cardiac arrest, spinal cord or nerve root injury, visual loss, death, shock, and others.

The purpose of this study was to identify the rate of inhospital complications following AIS corrective surgery and to identify independent factors associated with these adverse events. We hoped to aid surgeons and patients in preoperative risk analysis by examining the association between specific demographic, comorbid, and surgical parameters and complication occurrence.

\section{Methods}

\section{Study Design and Inclusion Criteria}

Using the Nationwide Inpatient Sample (NIS) databases for the years 2002 to 2011, we performed a retrospective review of patients who had undergone corrective surgery for AIS. The NIS is an inpatient database that contains hospitalization data for over 8 million admissions per year from a $20 \%$ sample of nonfederal hospitals in the United States (https://www.hcup-us.ahrq.gov/nisoverview. jsp). Data on diagnoses, procedures, and complications, all occurring within the same hospitalization, are recorded in the NIS in the form of International Classification of Diseases, 9th Revision (ICD-9) codes. Discharge weights (DISCWTs) are supplied for each admission and used to produce national estimates.

Patients with a discharge diagnosis of idiopathic scoliosis (code 737.30 ) were identified $(18,604)$. Those who did not undergo thoracolumbar stabilization procedures (codes 81.04-81.08) were excluded (1934). Patients under the age of 10 years (283) and over the age of 18 years (7189) were also excluded given the definition of AIS provided by the SRS. Lastly, nonelective admissions (1731) were also excluded. The final cohort of AIS patients consisted of 7467 admissions, which after the application of DISCWTs corresponded to 36,335 patients.

\section{Data Collection and Outcome Variables}

For each hospitalization, the following data were recorded: demographic data including patient age (10-14 vs $14-18$ years), sex, and primary payer; comorbidity data including anemia, heart failure, diabetes, drug abuse, hypertension, hypothyroidism, obesity, perivascular disease, and renal failure; and surgical data including primary or revision (spinal refusion) status, approach (posterior only, anterior only, or combined), use of recombinant human bone morphogenetic protein-2 (rhBMP-2), number of levels fused $(<8$ or $\geq 8)$, and use of osteotomy.

The primary outcome variable in this study was the development of at least one postoperative complication during the hospital stay. Complications consisted of wound complications such as surgical site infection (998.32, 998.51, 998.59, 998.6, and 998.83); implant-related complications (996.2, 996.40, 996.42, 996.47, 996.49, 996.63, 996.67, 996.75, 996.77, 996.78, 996.79, and 998.2); incidental durotomy (349.31 and 349.39); shock (998.00-998.9); accidental puncture or laceration of vessel, nerve, or organ (998.2); deep vein thrombosis (DVT) or pulmonary embolism (PE; 453.4-453.42, 453.8, 453.9, 415.22, 415.13, and 415.19); neurological complications (997.00-997.09); injury to spinal cord (952.0-952.9); injury to nerve roots or spinal plexus (953.0-953.9); sepsis (995.91); visual loss (368.11, 377.41, $377.75,362.3,362.30,363.31$, and 262.35); pneumonia (481, 482, and 483); myocardial infarction (410.0-410.91); respiratory failure (518.5-518.53, 518.81, 518.84, and 997.3); iatrogenic stroke (997.02); pancreatitis (557.0); reintubation (procedural code 96.04); malignant hyperthermia (995.86); cardiac complications (997.1); cardiac arrest (427.5); disseminated intravascular coagulation (286.6); and death. ${ }^{3,22}$

\section{Statistical Analysis}

All data were analyzed using Stata SE 12 (StataCorp LP) after the application of the DISCWTs supplied by the NIS and using the "survey" commands in the statistical program. A series of logistic regressions were used to determine if any demographic, comorbidity, or surgical variable was a predictor for complication development. Any parameter with a $\mathrm{p}$ value $<0.15$ was then included in a stepwise multiple regression model to assess the independent effect of any given exposure (dependent) variable on outcome. Results of logistic regressions are presented as odds ratios with their $95 \%$ confidence intervals. Statistical significance was defined as $p<0.05$. Given that the NIS does not allow publication of values $\leq 10$, certain parameters are expressed as "less than $n \%$," meaning that there were fewer than 11 occurrences in the database.

\section{Results}

After application of the DISCWTs, a total of 36,335 admissions were included in this study. Most patients were female $(75.2 \%)$ and the median age at surgery was 14 years. The overall complication rate was $7.6 \%$ (95\% CI $6.3 \%-8.9 \%$ ). The 5 most common complications were acute respiratory failure (3.47\%), reintubation (1.27\%), implant-related complications $(1.14 \%)$, cardiac complications $(0.93 \%)$, and pneumonia $(0.79 \%$; Table 1$)$.

Every major complication had an incidence of $0.2 \%$ or less: pancreatitis, disseminated intravascular coagulation, visual loss, spinal cord injury, cardiac arrest, sepsis, nerve root injury, DVT, PE, shock, malignant hyperthermia, myocardial infarction, and iatrogenic stroke. The mortality rate was less than $0.2 \%$.

\section{Demographic Parameters as Risk Factors}

The association between specific demographic parameters and complications is summarized in Table 2. After univariate analysis, an increasing age (OR 0.95 , 95\% CI 0.90 $0.99, \mathrm{p}=0.036$ ) was associated with lower odds of complication development. On the other hand, male patients (OR 1.79, $95 \%$ CI 1.48-2.17, p < 0.001) and patients with Medicaid as 
TABLE 1. Complications in AIS surgery in descending order of frequency

\begin{tabular}{lc}
\hline \multicolumn{1}{c}{ Complication } & Frequency \\
\hline Acute respiratory failure & $3.47 \%$ \\
\hline Reintubation & $1.27 \%$ \\
\hline Implant-related complication & $1.14 \%$ \\
\hline Cardiac complication & $0.93 \%$ \\
\hline Pneumonia & $0.79 \%$ \\
\hline Accidental vessel, nerve, or organ puncture & $0.53 \%$ \\
\hline Wound-related complication & $0.54 \%$ \\
\hline Neurological complication & $0.40 \%$ \\
\hline Pancreatitis & $0.20 \%$ \\
\hline Disseminated intravascular coagulation & $0.18 \%$ \\
\hline Incidental durotomy & $0.14 \%$ \\
\hline Visual loss & $0.14 \%$ \\
\hline Spinal cord injury & $0.12 \%$ \\
\hline Death & $0.12 \%$ \\
\hline Cardiac arrest & $0.09 \%$ \\
\hline Sepsis & $0.09 \%$ \\
\hline Nerve root injury & $0.04 \%$ \\
\hline DVT & $<0.03 \%$ \\
\hline PE & $<0.03 \%$ \\
\hline Shock & $<0.03 \%$ \\
\hline Malignant hyperthermia & $<0.03 \%$ \\
\hline Myocardial infarction & $0.0 \%$ \\
\hline latrogenic stroke & $0.0 \%$ \\
\hline
\end{tabular}

their insurer had significantly increased odds of developing a complication (OR 1.70, 95\% CI 1.13-2.56, $\mathrm{p}=0.011$ ).

\section{Medical Comorbidities as Risk Factors}

The overall comorbidity burden of the study population was low, and specific associations are summarized in Table 3. Patients with a history of anemia were 2.1 times more likely than those without this comorbidity to develop a complication (OR 2.10, 95\% CI 1.50-2.94, p < 0.001); this disorder was also the most common comorbidity, affecting $8.0 \%$ of the study population. Patients with heart failure (OR 13.88, 95\% CI 1.87-103.16, $\mathrm{p}=0.010)$, a history of drug abuse (OR 5.29, 95\% CI 0.94-29.93, $\mathrm{p}=0.059$ ), hypertension (OR 3.32, 95\% CI 1.79-6.15, p < 0.001), or hypothyroidism (OR 2.53, 95\% CI 1.18-5.47, $\mathrm{p}=0.018$ ) were also at an increased risk for complication development on univariate analysis.

\section{Surgical Parameters as Risk Factors}

Most patients (99.7\%) underwent primary fusion procedures and only $0.3 \%$ had revisions of previous fusion (Table 4). Most patients underwent a posterior approach (89\%), followed by those who underwent an anterior approach $(6 \%)$ or a combined approach $(5 \%)$. Recombinant human BMP-2 was used in $3.9 \%$ of cases, fusion of 8 or more spinal segments was performed in $68.1 \%$ of patients, and osteotomy was performed in $3.5 \%$. Interestingly, the number of segments fused was not associated with in-
TABLE 2. Demographic variables as risk factors for complications in AIS surgery

\begin{tabular}{lcccc}
\hline & $\begin{array}{c}\% \\
\text { Parameter }\end{array}$ & $\begin{array}{c}\% \text { Patients w/ } \\
\text { Patients }\end{array}$ & $\begin{array}{c}\text { Complications } \\
\text { OR }(95 \% \mathrm{Cl})\end{array}$ & $\begin{array}{c}\mathrm{p} \\
\text { Value }\end{array}$ \\
\hline Increasing age & - & & $0.95(0.90-0.99)$ & 0.036 \\
\hline Age & & & & \\
\hline $10-14$ & $57.8 \%$ & $7.8 \%$ & Reference & \\
\hline $14-18$ & $42.2 \%$ & $7.0 \%$ & $0.88(0.73-1.06)$ & 0.175 \\
\hline Sex & & & & \\
\hline Female & $75.2 \%$ & $6.5 \%$ & Reference & \\
\hline Male & $24.8 \%$ & $11.0 \%$ & $1.79(1.48-2.17)$ & $<0.001^{*}$ \\
\hline Primary payer & & & & \\
\hline Medicare & $0.11 \%$ & $0.0 \%$ & Reference & \\
\hline Medicaid & $24.4 \%$ & $9.9 \%$ & $1.70(1.13-2.56)$ & $0.011^{*}$ \\
\hline $\begin{array}{l}\text { Private in- } \\
\text { surance }\end{array}$ & $69 \%$ & $6.7 \%$ & $1.11(0.73-1.69)$ & 0.637 \\
\hline Other & $6.5 \%$ & $6.1 \%$ & - & - \\
\hline * Included in the multiple logistic regression model. & \\
\hline
\end{tabular}

* Included in the multiple logistic regression model.

creased morbidity (Fig. 1 upper). On univariate analysis, revision procedures (OR 6.04, 95\% CI, 2.28-16.02, $\mathrm{p}<$ 0.001 ), anterior approaches (OR 1.53, 95\% CI 1.00-2.32, $\mathrm{p}=0.045)$, and combined approaches (OR 3.38, 95\% CI 2.47-4.64, $\mathrm{p}<0.001$ ) were associated with an increased risk of complications compared with posterior approaches, the reference group (Fig. 1 lower).

\section{Independent Predictors of Complication Development}

On multiple logistic regression analysis, several independent predictors of postoperative complication development were identified (Fig. 2): increasing age (OR 0.80, 95\% CI $0.66-0.98, \mathrm{p}=0.034)$, male sex (OR $1.80,95 \%$ CI $1.45-2.22, \mathrm{p}<0.001$ ), anemia (OR 2.10, 95\% CI 1.51-2.91, $\mathrm{p}<0.001$ ), hypertension (OR 2.51, 95\% CI 1.33-4.72, $\mathrm{p}=$ 0.004 ), hypothyroidism (OR 2.27, 95\% CI 1.03-4.97, $\mathrm{p}=$ 0.039 ), revision procedures (OR 5.55, 95\% CI 2.10-14.61, $\mathrm{p}=0.001)$, anterior approaches (OR 1.71, 95\% CI 1.13$2.59, \mathrm{p}=0.011$ ), and combined approaches (OR 3.04, $95 \%$ CI $2.22-4.17, \mathrm{p}<0.001)$.

\section{Discussion}

Corrective surgery for AIS, as with any other spinal procedure, carries the risk of postoperative complications. ${ }^{7,28}$ The occurrence of adverse events is most likely a function of patient characteristics, comorbidity status, surgical technique and invasiveness, and surgeon dexterity, making risk stratification challenging. Nonetheless, identifying risk factors for complication development is important for both surgeons and patients, which was the main objective of this investigation.

We found a complication rate of $7.6 \%$ in 36,335 patients who had undergone spinal fusion for AIS, and the 5 most common adverse events were acute respiratory failure $(3.4 \%)$, reintubation $(1.3 \%)$, implant-related complications $(1.1 \%)$, cardiac complications ( $0.9 \%)$, and pneumonia $(0.8 \%)$. Pancreatitis, disseminated intravascular coagulation, visual loss, spinal cord injury, death, cardiac arrest, 
TABLE 3. Medical comorbidities as risk factors for complications in AIS surgery

\begin{tabular}{|c|c|c|c|c|}
\hline Parameter & $\begin{array}{c}\% \\
\text { Patients }\end{array}$ & $\begin{array}{l}\% \text { Patients w/ } \\
\text { Complications }\end{array}$ & OR $(95 \% \mathrm{Cl})$ & $\begin{array}{c}\mathrm{p} \\
\text { Value }\end{array}$ \\
\hline \multicolumn{5}{|l|}{ Anemia } \\
\hline No & $92.0 \%$ & $7.0 \%$ & Reference & \\
\hline Yes & $8.0 \%$ & $13.8 \%$ & $2.10(1.50-2.94)$ & $<0.001^{*}$ \\
\hline \multicolumn{5}{|l|}{ Heart failure } \\
\hline No & $99.05 \%$ & $7.6 \%$ & Reference & \\
\hline Yes & $0.05 \%$ & $53.3 \%$ & $13.88(1.87-103.16)$ & $0.010^{*}$ \\
\hline \multicolumn{5}{|l|}{ Diabetes } \\
\hline No & $99.6 \%$ & $7.6 \%$ & Reference & \\
\hline Yes & $0.4 \%$ & $7.7 \%$ & $1.01(0.25-4.13)$ & 0.989 \\
\hline \multicolumn{5}{|l|}{ Drug abuse } \\
\hline No & $99.92 \%$ & $7.6 \%$ & Reference & \\
\hline Yes & $0.08 \%$ & $30.3 \%$ & $5.29(0.94-29.93)$ & $0.059^{*}$ \\
\hline \multicolumn{5}{|l|}{$\begin{array}{l}\text { Hyperten- } \\
\text { sion }\end{array}$} \\
\hline No & $99.0 \%$ & $7.5 \%$ & Reference & \\
\hline Yes & $1.0 \%$ & $21.2 \%$ & $3.32(1.79-6.15)$ & $<0.001^{*}$ \\
\hline \multicolumn{5}{|l|}{$\begin{array}{l}\text { Hypothyroid- } \\
\text { ism }\end{array}$} \\
\hline No & $99.4 \%$ & $7.6 \%$ & Reference & \\
\hline Yes & $0.6 \%$ & $17.2 \%$ & $2.53(1.18-5.47)$ & $0.018^{*}$ \\
\hline \multicolumn{5}{|l|}{ Obesity } \\
\hline No & $98.2 \%$ & $7.5 \%$ & Reference & \\
\hline Yes & $1.8 \%$ & $11.7 \%$ & $1.62(0.96-2.73)$ & $0.068^{*}$ \\
\hline \multicolumn{5}{|l|}{$\begin{array}{l}\text { Perivascular } \\
\text { disease }\end{array}$} \\
\hline No & $99.88 \%$ & $7.6 \%$ & Reference & \\
\hline Yes & $0.12 \%$ & $11.0 \%$ & $1.50(0.19-12.05)$ & 0.701 \\
\hline \multicolumn{5}{|l|}{ Renal failure } \\
\hline No & 99.92 & $7.6 \%$ & Reference & \\
\hline Yes & $0.08 \%$ & $17.1 \%$ & $2.51(0.29-21.90)$ & 0.403 \\
\hline
\end{tabular}

* Included in the multiple logistic model.

sepsis, nerve root injury, DVT, PE, shock, and malignant hyperthermia, which can all be categorized as major complications, each had an incidence $\leq 0.2 \%$. Similar to us, the SRS found a complication rate of $5.7 \%$ after examining 6334 procedures, ${ }^{7}$ and their most common complication was pulmonary. Their rates for posterior, anterior, and combined approaches were $1.0 \%, 1.6 \%$, and $3.5 \%$, respectively. Major neurological complications such as spinal cord injury occurred in $0.28 \%$ of all cases $(0.21 \%$ of posterior approaches and $1.12 \%$ of combined procedures).

Respiratory complications remain a significant cause of postoperative morbidity following scoliosis surgery. Multiple studies have shown that they are some of the most common complications after spinal deformity surgery, ${ }^{7,9,11}$, 15,25 and AIS surgery is no exception. Thus, respiratory complications may be a function of both the procedure (as in pain-related atelectasis) and the preoperative respiratory functional status of the patient. Adolescent idiopathic scoliosis patients may have alterations in pulmonary function
TABLE 4. Surgical parameters as risk factors for complications in AIS surgery

\begin{tabular}{|c|c|c|c|c|}
\hline Parameter & $\begin{array}{c}\% \\
\text { Patients }\end{array}$ & $\begin{array}{l}\% \text { Patients w/ } \\
\text { Complications }\end{array}$ & OR $(95 \% \mathrm{Cl})$ & $\begin{array}{c}p \\
\text { Value }\end{array}$ \\
\hline \multicolumn{5}{|l|}{ Procedure } \\
\hline Primary & $99.7 \%$ & $7.5 \%$ & Reference & \\
\hline Revision & $0.3 \%$ & $33.0 \%$ & $6.04(2.28-16.02)$ & $<0.001^{*}$ \\
\hline \multicolumn{5}{|l|}{ Approach } \\
\hline $\begin{array}{c}\text { Posterior } \\
\text { only }\end{array}$ & $89.0 \%$ & $6.7 \%$ & Reference & \\
\hline $\begin{array}{c}\text { Anterior } \\
\text { only }\end{array}$ & $6.0 \%$ & $10.0 \%$ & $1.53(1.00-2.32)$ & $0.045^{*}$ \\
\hline Combined & $5.0 \%$ & $19.8 \%$ & $3.38(2.47-4.64)$ & $<0.001^{*}$ \\
\hline \multicolumn{5}{|l|}{$\begin{array}{l}\text { Use of } \\
\text { rhBMP-2 }\end{array}$} \\
\hline No & $96.1 \%$ & $7.6 \%$ & Reference & \\
\hline Yes & $3.9 \%$ & $8.5 \%$ & $1.13(0.78-1.66)$ & 0.502 \\
\hline \multicolumn{5}{|l|}{$\begin{array}{l}\text { No. of levels } \\
\text { fused }\end{array}$} \\
\hline$<8$ & $31.9 \%$ & $6.7 \%$ & Reference & \\
\hline$\geq 8$ & $68.1 \%$ & $7.5 \%$ & $1.13(0.89-1.46)$ & 0.311 \\
\hline \multicolumn{5}{|l|}{ Osteotomy } \\
\hline No & $96.5 \%$ & $7.5 \%$ & Reference & \\
\hline Yes & $3.5 \%$ & $9.5 \%$ & $1.29(0.78-2.15)$ & 0.326 \\
\hline
\end{tabular}

* Included in the multiple logistic regression model.

if they have severe curves (Cobb angle $>60^{\circ}$ ) and depending on the curve level and degree of spinal rotation. ${ }^{25}$ Risk factors for respiratory complications include low preoperative vital capacity, underlying lung disease, heart failure, obesity, anterior approaches, and others. ${ }^{1}$ Measures such as preoperative nutritional optimization, inceptive spirometry, early patient mobilization, and chest physical therapy may help reduce respiratory complications. ${ }^{1}$

On risk factor analysis, we found that male patients were significantly more likely than females to develop a complication. Males with AIS tend to present at an older age and with more rigid curves than females, which could explain their increased morbidity risk. ${ }^{18,24}$ Patients with a history of anemia, hypertension, and hypothyroidism were also more likely to develop a complication. Though adolescents have less comorbidity than their adult counterparts, surgeons and patients should acknowledge the potentially increased risk of adverse events in this younger population. A study by Vigneswaran et al. found that the average number of comorbid conditions in patients who had undergone combined approaches for AIS increased significantly from 4.3 in the year 1997 to 6.4 in the year $2012 .{ }^{27}$ As the comorbidity rates of patients increase, it is even more important to recognize these conditions for risk stratification and surgical planning.

Perioperative optimization of patients with certain comorbid conditions may decrease the postoperative complication rates. For example, although there is no universal consensus regarding the threshold for blood transfusion in scoliosis surgery, we recommend keeping hemoglobin levels above $8 \mathrm{~g} / \mathrm{dl}$ in pediatric patients..$^{10} \mathrm{In}$ a retrospec- 

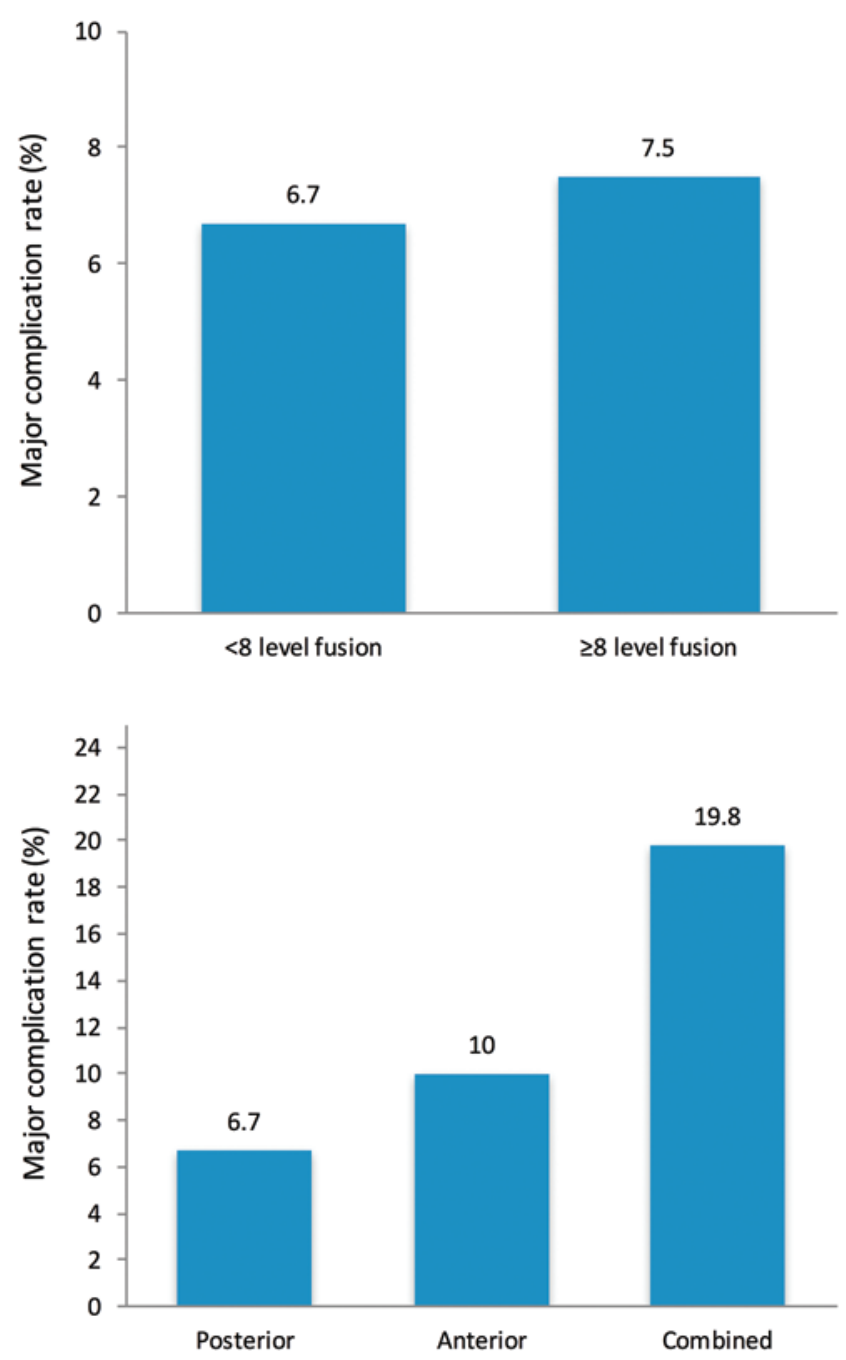

FIG. 1. Relationship between surgical parameters and in-hospital postoperative complication rates. Upper: The rate of complications between fusion procedures involving $<8$ levels and those involving $\geq 8$ was not significantly different ( $p=0.311$, chi-square test). Lower: Complication rates based on approach were significantly different $(p<0.001$, chi-square test). Figure is available in color online only.

tive study of 86 patients who underwent surgery for AIS, van Popta et al. found an average hemoglobin decrease of $4.1 \mathrm{~g} / \mathrm{dl}$ within the first 2 postoperative days. ${ }^{26}$ These authors recommended a minimum preoperative hemoglobin value $5 \mathrm{~g} / \mathrm{dl}$ higher than the transfusion threshold, which is around $7-8 \mathrm{~g} / \mathrm{dl}$ depending on the institution and the specific practice. Similarly, preoperative optimization strategies for patients with hypertension or hypothyroidism may further decrease postoperative complication rates, but further research is needed to develop appropriate guidelines.

Several surgical parameters were analyzed to determine their independent effect on complication development. Notably, the use of rhBMP-2, use of osteotomy, and length of fusion were not correlated with adverse events. On the other hand, revision status and surgical approaches were significantly associated with adverse events, with rates of $6.7 \%, 10.0 \%$, and $19.8 \%$ for posterior, anterior, and combined approaches, respectively $(\mathrm{p}<0.001)$. Notably, revi- sion procedures were among the top risk factors for complications in our study (OR 5.55). In the SRS morbidity and mortality database, Fu et al. analyzed data on 23,918 pediatric patients who had undergone spinal surgery for scoliosis, kyphosis, spondylolisthesis, trauma, and other disorders, noting that revision procedures increased the risk of complications. ${ }^{11}$ They found a $12 \%$ complication rate for revisions, compared with $8 \%$ for primary procedures; specific adverse events that were more common in the revision group included deep wound infection (4\% vs $1.4 \%$ ), durotomy $(0.9 \%$ vs $0.4 \%)$, implant-related complications ( $3 \%$ vs $1.4 \%)$, and new neurological deficits (1.9\% vs $1.3 \%){ }^{11}$ Though revision procedures were uncommon in our study (only $0.3 \%$ of the population), this was most likely attributable to the fact that revisions are more common later in adulthood and thus were not included in our investigation.

Also commensurate with our findings was a higher complication rate for combined approaches in AIS surgery according to Coe et al., who found a rate of $10.2 \%$, compared with $5.1 \%$ for posterior approaches and 5.2\% for anterior approaches. In a study of risk factors for complication development in adult spinal deformity, Schwab et al. found that $56 \%$ of patients who developed a complication had undergone a combined anterior and posterior approach, compared with $32 \%$ of patients in the control group $(\mathrm{p}=0.011) .{ }^{22}$ Although combined approaches may predispose to an increased risk of complications, certain deformities may require such approaches. Anterior release (with or without instrumentation) followed by posterior fixation is typically indicated in cases of large curves (Cobb angle above $70^{\circ}-80^{\circ}$ ), excessively rigid curves not corrected to less than $60^{\circ}$ on side-bending films, curves with severe thoracic kyphosis, and for the prevention of the crankshaft phenomenon in skeletally immature adolescents..$^{20}$ Nevertheless, newer techniques have allowed for similar results in terms of degree of correction and outcomes for posterior-only approaches, with less postoperative morbidity, lower blood loss, and shorter stay. ${ }^{5}$

Though construct length ${ }^{29}$ and osteotomy ${ }^{6,21}$ have been associated with higher rates of adverse events in corrective surgery for adult scoliosis, we found no evidence of these associations for the AIS patients in the present study. Daubs et al. noted that once the fusion length reaches 5 or more levels in adult spinal deformity, the addition of more segments may not necessarily increase complication rates, ${ }^{8}$ and since AIS patients generally have more than 5 levels fused, it is possible that Daubs et al.'s finding also applies to the AIS population. Osteotomies are relatively uncommon in the pediatric and adolescent population given that most cases of deformity in such patients are flexible; indications for osteotomy include fixed deformity (such as previously fused segments) or severe focal kyphoscoliosis. ${ }^{12}$ Boachie-Adjei et al. found that osteotomy, specifically vertebral column resection, was an independent risk factor for complications (OR 3.06, 95\% CI 1.14-8.19) in patients with severe deformities (average Cobb angle $89.1^{\circ}$ ). ${ }^{2}$ Similarly, Lenke et al. found a complication rate of $59 \%$ for pediatric patients undergoing vertebral column resection for severe deformity. ${ }^{17}$ Though the exact reason for our findings is unknown, it is possible that younger patients with AIS have a healthier profile than adults with spinal deformity and 


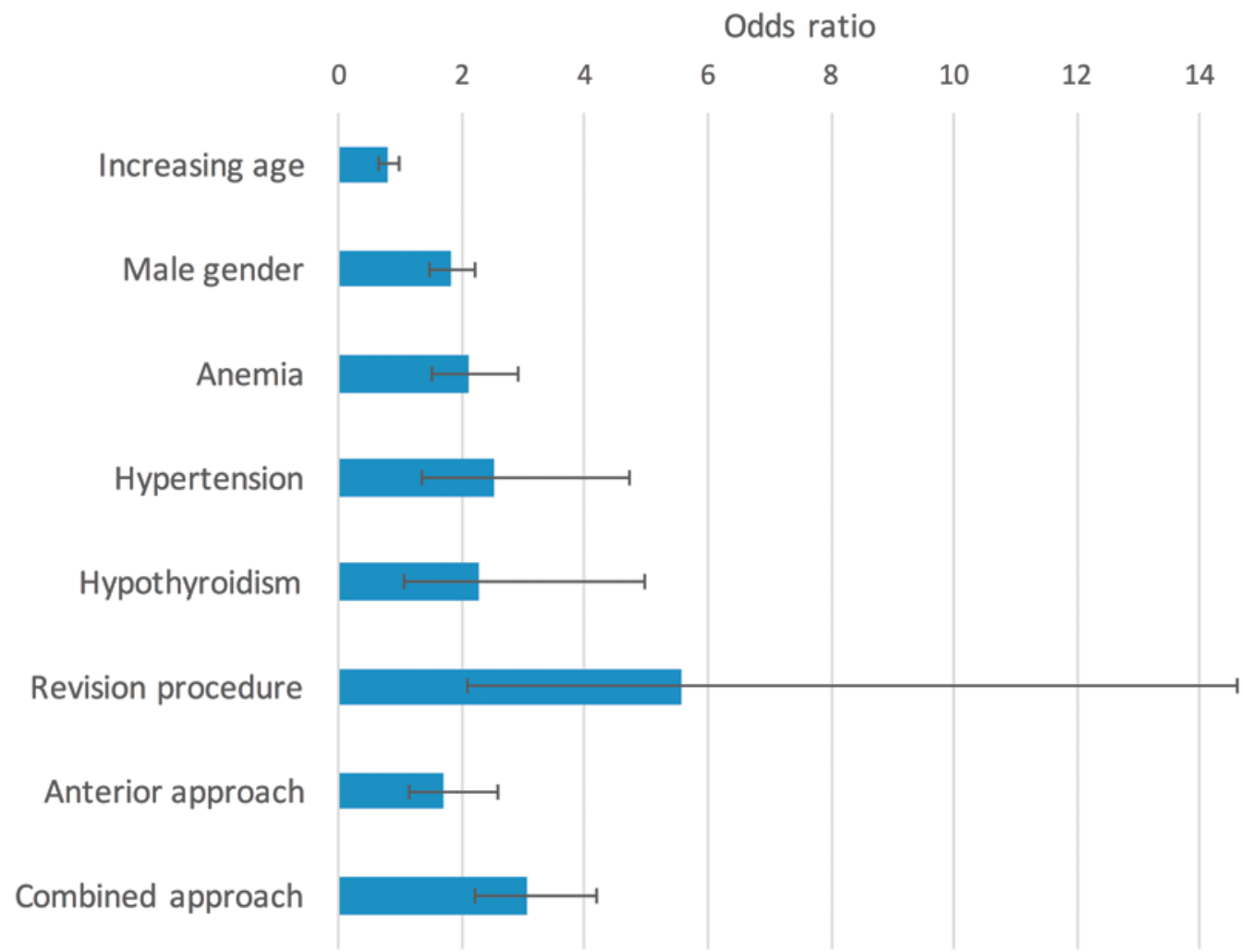

FIG. 2. Independent factors associated with complication development. Error bars correspond to $95 \%$ confidence intervals. Figure is available in color online only.

thus are less likely to develop a postoperative complication. Nonetheless, our findings warrant further investigation, ideally in the form of prospective multicenter collaborations.

\section{Study Strengths and Limitations}

This study represents a valuable investigation of inhospital postoperative complication rates (including major complications) in patients who underwent surgery for AIS. The sample size is one of the largest to date, and our results are consistent with other reports in the literature, suggesting that AIS surgery is relatively safe and that major complications are uncommon. Through the identification of factors associated with complications, surgeons and patients may become aware of the specific risks of corrective surgery. Nevertheless, this study has several limitations inherent to the use of an administrative database such as the NIS. Though multiple studies have used this database to report short-term outcomes in spine surgery, ${ }^{13,19,27,29-31}$ reliance on ICD-9 codes to identify diagnoses, procedures, and complications carries the risk of coding bias and limitations in the use of predetermined codes. For example, though osteotomy was identified through a procedural code, it is unclear whether the code corresponded to a Smith-Petersen osteotomy, Ponte osteotomy, pedicle subtraction osteotomy, or vertebral column resection. Given that the NIS is not specific to spine surgery, other parameters such as radiographic measurements, curve types, neurological status, and long-term results are not available. Lastly, the NIS contains only inpatient data, meaning that complications, including deaths, occurring after discharge are not captured.
In the future, prospective investigations should help to better delineate the risks associated with AIS surgery. Ideal studies would consist of preoperative patient surveys containing health-related quality of life outcome measures, radiographic parameters, assessment of cardiopulmonary function, assessment of neurological function, and others. Complications would be recorded, and patients would be followed up for at least 2-5 years postoperatively to assess any long-term complications such as delayed wound infection, instrumentation failure, and need for revision surgery, as well as quality of life outcome measures.

\section{Conclusions}

After an analysis of data for 36,355 patients who had undergone corrective surgery for AIS, we found that the risk for postoperative complication was $7.6 \%$, with individual major complications having an incidence of $0.2 \%$ or less. Male patients and patients with a history of anemia, hypertension, or hypothyroidism had an increased risk of adverse events. Revision procedures, anterior approaches, and combined approaches also increased the risk of complications. Nonetheless, surgery for AIS remains a relatively safe procedure, and future prospective investigations may further help to decrease complication rates.

\section{References}

1. Baron EM, Albert TJ: Medical complications of surgical treatment of adult spinal deformity and how to avoid them. Spine (Phila Pa 1976) 31 (19 Suppl):S106-S118, 2006 
2. Boachie-Adjei O, Yagi M, Nemani VM, Sacramento-Dominguez $\mathrm{C}$, Akoto $\mathrm{H}$, Cunningham ME, et al: Incidence and risk factors for major surgical complications in patients with complex spinal deformity: a report from an SRS GOP site. Spine Deform 3:57-64, 2015

3. Carreon LY, Puno RM, Dimar JR II, Glassman SD, Johnson JR: Perioperative complications of posterior lumbar decompression and arthrodesis in older adults. J Bone Joint Surg Am 85-A:2089-2092, 2003

4. Carreon LY, Puno RM, Lenke LG, Richards BS, Sucato DJ, Emans JB, et al: Non-neurologic complications following surgery for adolescent idiopathic scoliosis. J Bone Joint Surg Am 89:2427-2432, 2007

5. Chen Z, Rong L: Comparison of combined anterior-posterior approach versus posterior-only approach in treating adolescent idiopathic scoliosis: a meta-analysis. Eur Spine J 25:363-371, 2016

6. Cho SK, Bridwell KH, Lenke LG, Yi JS, Pahys JM, Zebala LP, et al: Major complications in revision adult deformity surgery: risk factors and clinical outcomes with 2- to 7-year follow-up. Spine (Phila Pa 1976) 37:489-500, 2012

7. Coe JD, Arlet V, Donaldson W, Berven S, Hanson DS, Mudiyam R, et al: Complications in spinal fusion for adolescent idiopathic scoliosis in the new millennium. A report of the Scoliosis Research Society Morbidity and Mortality Committee. Spine (Phila Pa 1976) 31:345-349, 2006

8. Daubs MD, Lenke LG, Cheh G, Stobbs G, Bridwell KH: Adult spinal deformity surgery: complications and outcomes in patients over age 60. Spine (Phila Pa 1976) 32:22382244, 2007

9. De la Garza-Ramos R, Jain A, Kebaish KM, Bydon A, Passias PG, Sciubba DM: Inpatient morbidity and mortality after adult spinal deformity surgery in teaching versus nonteaching hospitals. J Neurosurg Spine [epub ahead of print March 4, 2016. DOI: 10.3171/2015.11.SPINE151021]

10. De la Garza-Ramos R, Samdani AF, Sponseller PD, Ain MC, Miller NR, Shaffrey CI, et al: Visual loss after corrective surgery for pediatric scoliosis: incidence and risk factors from a nationwide database. Spine J 16:516-522, 2016

11. Fu KM, Smith JS, Polly DW, Ames CP, Berven SH, Perra JH, et al: Morbidity and mortality associated with spinal surgery in children: a review of the Scoliosis Research Society morbidity and mortality database. J Neurosurg Pediatr 7:37-41, 2011

12. Gokcen B, Yilgor C, Alanay A: Osteotomies/spinal column resection in paediatric deformity. Eur J Orthop Surg Traumatol 24 (Suppl 1):S59-S68, 2014

13. Jain A, Sponseller PD, Kebaish KM, Mesfin A: National trends in spinal fusion surgery for Scheuermann kyphosis. Spine Deform 3:52-56, 2015

14. James JI: Idiopathic scoliosis; the prognosis, diagnosis, and operative indications related to curve patterns and the age at onset. J Bone Joint Surg Br 36-B:36-49, 1954

15. Jules-Elysee K, Urban MK, Urquhart BL, Susman MH, Brown AC, Kelsey WT: Pulmonary complications in anteriorposterior thoracic lumbar fusions. Spine J 4:312-316, 2004

16. Kepler CK, Meredith DS, Green DW, Widmann RF: Longterm outcomes after posterior spine fusion for adolescent idiopathic scoliosis. Curr Opin Pediatr 24:68-75, 2012

17. Lenke LG, Newton PO, Sucato DJ, Shufflebarger HL, Emans JB, Sponseller PD, et al: Complications after 147 consecutive vertebral column resections for severe pediatric spinal deformity: a multicenter analysis. Spine (Phila Pa 1976) 38:119-132, 2013

18. Patil CG, Santarelli J, Lad SP, Ho C, Tian W, Boakye M: Inpatient complications, mortality, and discharge disposition after surgical correction of idiopathic scoliosis: a national perspective. Spine J 8:904-910, 2008

19. Paul JC, Lonner BS, Toombs CS: Greater operative volume is associated with lower complication rates in adolescent spinal deformity surgery. Spine (Phila Pa 1976) 40:162-170, 2015

20. Rauzzino MJ, Shaffrey CI, Wagner J, Nockels R, Abel M: Surgical approaches for the management of idiopathic thoracic scoliosis and the indications for combined anteriorposterior technique. Neurosurg Focus 6(5):e6, 1999

21. Reames DL, Smith JS, Fu KM, Polly DW Jr, Ames CP, Berven SH, et al: Complications in the surgical treatment of 19,360 cases of pediatric scoliosis: a review of the Scoliosis Research Society Morbidity and Mortality database. Spine (Phila Pa 1976) 36:1484-1491, 2011

22. Schwab FJ, Hawkinson N, Lafage V, Smith JS, Hart R, Mundis G, et al: Risk factors for major peri-operative complications in adult spinal deformity surgery: a multi-center review of 953 consecutive patients. Eur Spine J 21:2603-2610, 2012

23. Sud A, Tsirikos AI: Current concepts and controversies on adolescent idiopathic scoliosis: Part I. Indian J Orthop 47:117-128, 2013

24. Suh PB, MacEwen GD: Idiopathic scoliosis in males. A natural history study. Spine (Phila Pa 1976) 13:1091-1095, 1988

25. Tsiligiannis T, Grivas T: Pulmonary function in children with idiopathic scoliosis. Scoliosis 7:7, 2012

26. van Popta D, Stephenson J, Patel D, Verma R: The pattern of blood loss in adolescent idiopathic scoliosis. Spine J 14:2938-2945, 2014

27. Vigneswaran HT, Grabel ZJ, Eberson CP, Palumbo MA, Daniels AH: Surgical treatment of adolescent idiopathic scoliosis in the United States from 1997 to 2012: an analysis of 20,346 patients. J Neurosurg Pediatr 16:322-328, 2015

28. Weiss HR, Goodall D: Rate of complications in scoliosis surgery - a systematic review of the PubMed literature. Scoliosis 3:9, 2008

29. Worley N, Marascalchi B, Jalai CM, Yang S, Diebo B, Vira S, et al: Predictors of inpatient morbidity and mortality in adult spinal deformity surgery. Eur Spine J 25:819-827, 2016

30. Yoshihara H, Yoneoka D: National trends in spinal fusion for pediatric patients with idiopathic scoliosis: demographics, blood transfusions, and in-hospital outcomes. Spine (Phila Pa 1976) 39:1144-1150, 2014

31. Yoshihara H, Yoneoka D: Predictors of allogeneic blood transfusion in spinal fusion for pediatric patients with idiopathic scoliosis in the United States, 2004-2009. Spine (Phila Pa 1976) 39:1860-1867, 2014

\section{Disclosures}

Dr. Sciubba has consulting relationships with Medtronic, DePuySynthes, Globus, Orthofix, and Stryker.

\section{Author Contributions}

Conception and design: Sciubba, De la Garza Ramos. Acquisition of data: De la Garza Ramos, Goodwin, Abu-Bonsrah, Jain, Miller, Huang. Analysis and interpretation of data: De la Garza Ramos, Goodwin, Abu-Bonsrah, Jain, Miller, Huang, Kebaish, Sponseller. Drafting the article: all authors. Critically revising the article: Sciubba, De la Garza Ramos, Goodwin, Jain, Miller, Kebaish, Sponseller. Reviewed submitted version of manuscript: Sciubba, De la Garza Ramos. Approved the final version of the manuscript on behalf of all authors: Sciubba. Statistical analysis: De la Garza Ramos, Jain. Study supervision: Sciubba, Kebaish, Sponseller.

\section{Correspondence}

Daniel M. Sciubba, Department of Neurosurgery, The Johns Hopkins Hospital, 600 North Wolfe St., Meyer 5-185, Baltimore, MD 21287.email: dsciubb1@jhmi.edu. 